\title{
$\operatorname{cron} F-831111-8$
}

UCRL--89602

DE83 017618

\section{COMPUTER IMPLEMENTATION, ACCURACY, AND TIMING OF RADIATION VIEW-FACTOR ALGORITHMS}

Arthur B. Shapiro

This paper was prepared for submittal to the 1983 ASME Winter Meeting, Boston, MA. November $14-18,1983$

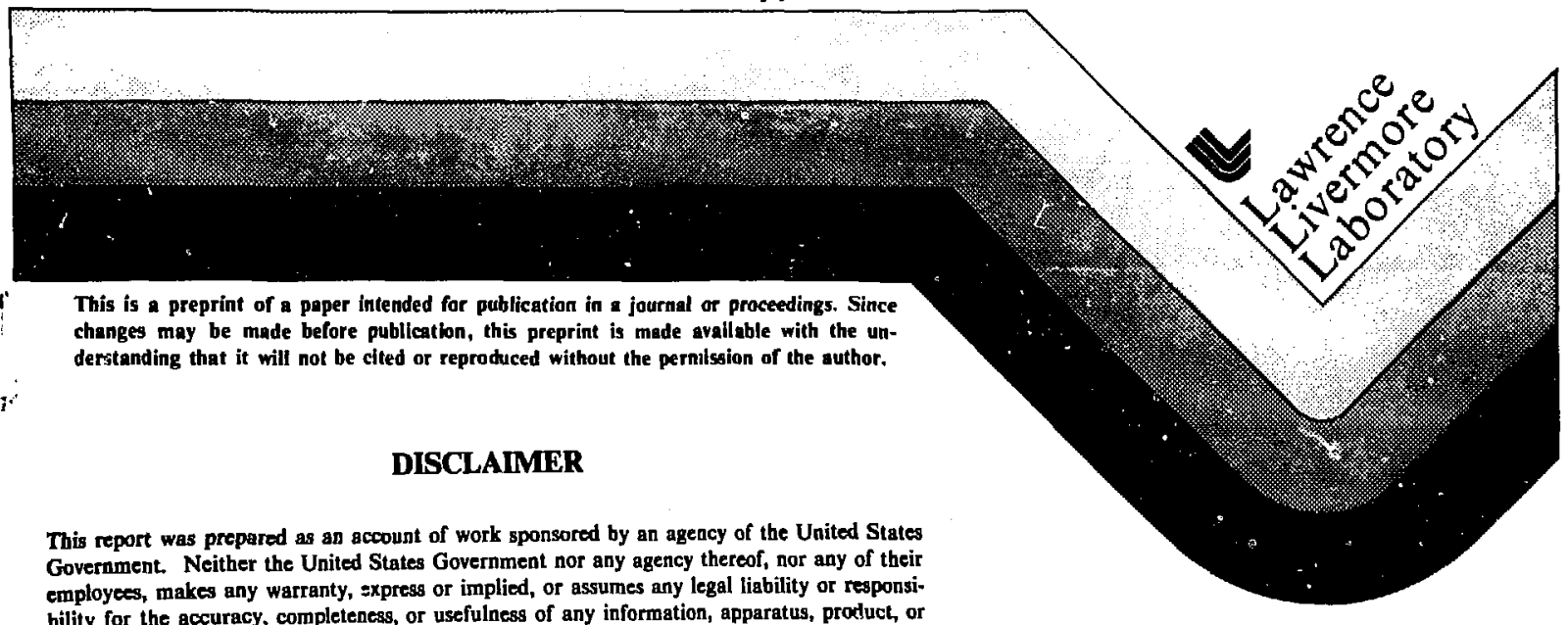
cheplity process disclosed, or represents that its use would not infringe privately owned rights. Reference herein to any specific commercial product, process, or service by trade asme, trademark, manufacturen, or otherwise does not necessarily constitute or imply its endorsement, recommendation, or favoring by the United States Government or any agency thereof. The views and opinions of authors expressed herein do not necessarily state or reflect those of the United States Government or any agency thereof. 


\section{COMPUTER IMPLEMENTATION, ACCURACY AND TIMING OF RADIATION VIEW-FACTOR ALGORITHMS}

Arthur B. Shapiro

University of California, Laurence Livermore National Laboratory

Livermore, California 94550 , U.S.A.

\section{ABSTRACT}

The chree-dimensional $f$ inite-element thermal analysis of enclosure radiation problems requires the calculation of the geametric surface-tonsurface radiation vieu factors. The vieu factors can be calculaced by either area or line integration algorithms. This paper addresses the implementation, accuracy, and computational time involved in using these algorichms. Additionally, an algorithm to identify shadowing surfaces and methods to adjust the calculated vieu factors for increased accuracy are presented.

\section{INTRODUCTION}

At the Lawrence Livermore Narional Laboratory several proiects require the three-dimensional finite - lement thermal analysis of problems involving conduction in a solid coupled with radiation in enclosures within the solid. An enclosure is defined by the discrete boundary surfaces of finite elements which surraund the enclosure and define che solid ohject. Other objects, such as radiation shields, mav he present within the enclosure. To calculate the ratiation transport within che enclosure, thr yeometric surface to surface black body radiation vieu factors are required. Several computer codes $(1-3)$ are available to calculate the view factor between two surfaces with the possibility of third surface shadowing. These codes use either area or line integration algorithmg to calculate view factors without shadowing. In the presence of shadowing, ald these codes use area incegration algorithms with various techniques to account for the ahadowing. Extensive computations at LLNL in solving large two-dimensional enclosure radiation problems with 700 to 1000 participating segments revealed that up to chree hours of computer time ${ }^{l}$ vere required to

IA CRAY-1 computer was used for all computations. The CRAY- 1 has a 64 bit word length and an add time of 0.025 to 0.075 usec. calculate vieu factors. The subsequent steady state thermal analysis using these view factors required under 20 minutes of computation $t$ ime. The inaccuracies in the final results were attributable to inaccurate view factors between surfaces with chird surface shadowing. As a result of chis experience, before extending our analyses to three dimensions, the conputational timing and accuracy of the various chree-dimensional view factor algorichng needed to be quantified. This paper addresses the computer implementation, accuracy and computational time involved in using these algorithms. Additionally, an algorithm to identify shadowing surfaces and methods to adjust the calculated view factors for increased accuracy are presented.

\section{VIEW FACTOR ALGORITHMS}

The geometric black body radiation vieu factor hetween two surfaces, Fig. 1 , is

$$
F_{I J}=\frac{1}{A_{1}} \int_{A_{I} A_{J}} \frac{\cos A_{I} \cos A_{j} d A_{I} d A_{3}}{\pi r^{2}}
$$

If the two surfaces $A$, and $A$, are divided into $n$ finite substrfaces $A_{i}: i=1,2, \ldots, n$ and $A_{j}: j=1,2, \ldots, n$, Eq. ( 1 ) may be approximaced by

$$
F_{I J}=\frac{1}{n_{I}} \sum_{i=1}^{n} \sum_{j=1}^{n} \frac{\cos A_{i} \cos \theta_{j} A_{i} A_{j}}{\pi r_{i j}^{2}}
$$

The computational scheme, Eq. ( 2 ), is referred to as double area sumation and is used in the computer codes $(1-3)$ if shadowing exists.

The area integrals in Eq. (1) can be transformed to line integrals by using Stokes' theorem ( $\underline{5})$. The result is

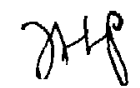




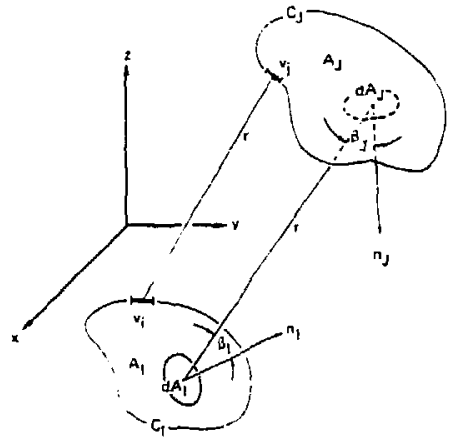

FIG. I THIS SKETCH ILLUSTRATES THE SYMOLS USED IN EQS. (1) THROUGH (4) TO CALCULATE THE VIEW FACTOR F[-].

$$
\begin{array}{r}
F_{I J}=\frac{b}{2 \pi A_{I}}{\underset{C}{C_{I}} \oint_{C_{J}}\left(\ln r d x_{I} d x_{J}\right.}^{\left.+\ln r d y_{I} d y_{J}+\ln r d x_{t} d z_{J}\right)}
\end{array}
$$

If the two contours $C_{1}$ and $C_{J}$ are divisied into $n$ Finite sraight $l$ ine segments $\hat{v}_{i}: i=1,2, \ldots, n$ and $\hat{v}_{j}: j=1,2, \ldots, n$, Eq. (3) mav be approximated by

$$
F_{I J}=\frac{1}{2 \pi A_{1}} \sum_{i=1}^{n} \sum_{j=1}^{n} \text { Qn } r_{i j} \hat{v}_{i} \cdot \hat{v}_{j}
$$

Mitalas and Stephenson (4) present a method by which one of the interrals in Eq. (3) can be inteRrated analutically. If the gurfaces $I$ and $J$ are quadrilaterals, the result is

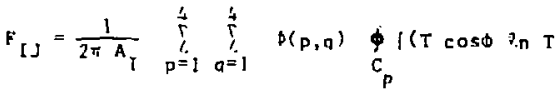

$$
\begin{aligned}
& +S \cos \theta \text { P.n } S+U t u-R) d v]_{P, q}
\end{aligned}
$$

where 5, T, U, D, and ware functions of $y$ and

$$
p(p, q)=q_{p} p_{q}+m_{p} m_{q}+\pi_{p} n_{q}
$$

The symbols are defined in Fig. 2. Dividing each of the four line gegments $C$ into $n$ finite straight line segments $j_{j}: j=1,2, \ldots, n$, Eq. (5) may be approximated $F_{I J}=\frac{1}{2 \pi A_{T}} \sum_{p=1}^{4} \sum_{q=1}^{4} \theta(p, q) \sum_{j=1}^{n} I(T \cos \phi \theta n T$

$$
+5 \cos \theta \ln 5+(t+1)-R)\left.\left|\bar{v}_{j}\right|\right|_{p, q}
$$

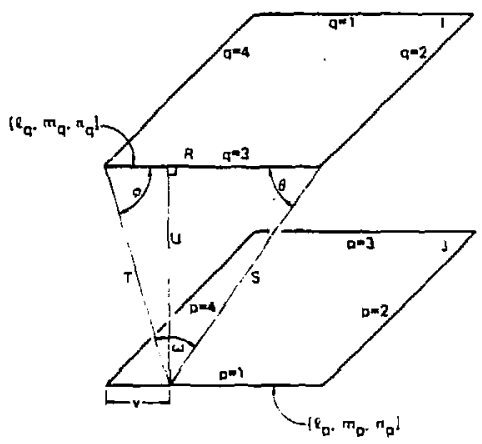

FIG. 2 THIS SKETCH ILLUSTRATES THE SYHBOLS USED IN MITALAS AND STEPHENSON'S CONTOUR INTEGRATION METHOD, EQS. (5) AND (6), TO CALCULATE THE VIEW FACTOR $F_{\mathrm{I}-\mathrm{J}}$.

The computational schemes represented by Eqs. (2), (4), and (7) will subsequently be referred to as the area integracion method (AL). Iine integration method (LI), and the Mitalas and stephenson method (MS), respectively. The surfaces between which view factors are being calculated are plane quadrilaterals. Methods LI and MS require a subdivision of the contour of the quadrilaceral while methot AI requires a subJivision of the surface area. Dividing each of the four line segments forming the quadrilateral into $n$ Nivisions results in a cotal of $4 n$ nodes around the contour and $n^{2}$ nodes for the surface area.

Operation councs for the three methods are:

$$
\begin{array}{ll}
\text { AI Mechod } & 114 n^{4}+86 n^{2} \\
\text { LI Method } & 464 n^{2}+24 r \\
\text { MS Method } & 864 n+288
\end{array}
$$

Timing studies, Fig. 3, shor that the LI method is faster than the A method for $n \geq 2$. Coding of the I method results in FORTRAN Do - loops which are vectorized by the CRAY CFT ( 6 ) compiler. As a result of vectorization, the $L I$ merhod having more operations is fascer than the MS method for $n<18$. Timing scudies for the $L I$ and MS methods are presenced in Fip. 4 .

The use of the numerical approximations for calculating the vieu factor, Eqs. (2), (4), and (7), assumes that the distance between the two surfaces is large compared to the differential approximates $A_{t}$, $A_{j}$ and $v_{j}$. As the distance between the two surfaces approaches the magnitude of $A_{i}, A_{j}$, and $\vec{v}_{j}$, the calculated viev factor becomes increasingly inaceurate. This is shown in Fig. 5 where the separation distance between two directly opposed $|x|$ squares is decreased from 10 to 1 . The jeast accurate solution exists when the two surfaces share a common edge. To obtain a greater accuracy in the numerical calculations, the number of nodes, $\pi$, should be increased. Figures $h$ and 7 ahow the percent error as a function of the number of nodes for directly opposed $|x|$ squares and 


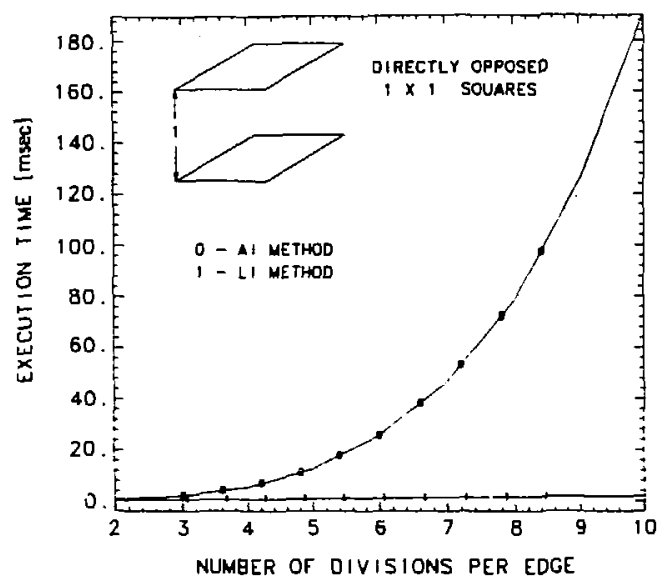

FIG. 3 AN OPERATION COUNT SHOWED THAT $114 n^{4}+85 n^{2}$ and $464 n^{2}+24 n$ ORERATLONS ARE REQUIRED FOR THE AI and LI METHODS, RESPECTIVELY. THE LI METHOD IS FASTER THAN THE AI METHOD FOR $n>2$.

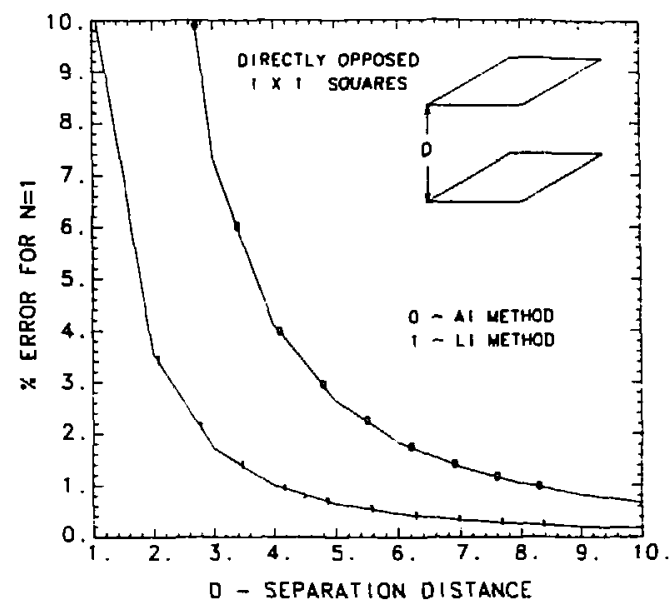

FIC. 5 THE USE OF THE NUMERICAL APPROXIMATIONS FOR CALCULATING THE VIEW FACTOR, EQS. (2), (4), AND (7), ASSUMES THAT THE DISTANCE BETLEEN THE TWO SURFACE 5 IS LARGE COMPARED TO THE DIFFERENT IAL APPROXIMATES $A_{i}, A_{j}$, and $v_{j}$. AS THE DISTANCE BETTEEN THE TWO SURFACES APPROACHES THE MAGNITUDE OF $A_{1}, A_{j}$, AND $\hat{v}_{j}$, THE CALCULATED VIEH FACTOR BECOHES INCREASINGLY INACCURATE.



FIG. A THE LINE INTEGRATION METHODS, LI AND MS, ARE SIGNIFICANTLY MORE ACCURATE THAN THE AREA INTEGRATION METHOD AI. THE HS METHOD HAVING ONE OF ITS LINE IHTEGRALS PERFORMED ANALYTLCALLY IS MORE ACCURATE THAN THE LI METHOD. 
perpendicular $1 \times 1$ squares, respectively. The line integration methods, LI and MS, are significantly more accurace than the area integration method AI. The MS method having one of itg line incegrals performed analycically is more accurate than the LI method. The AI method is so inaccurate when the tro aurfaces share a common edge, Fig. 7, that it should not be used.

In conclusion, the AI method should not be used. The LI method is less accurate but the execution time is faster chan the MS method. Based on accuracy and execution time, Fig. 8, the LI method is superior co the MS method for $n<7$. For geometries other than directly opposed $1 \times l$ squares with a geparation distance of 1 , the value of $n$ for the breakeven point is of course different.

\section{SHADOWING AND OBSTRUCTIONS}

Three types of shadowing may exist between two surfaces. There may be total self shadowing, partial self shadowing, and third surface shadowing. Tatal or pertial self shadouing can be deterted betueen two surfaces by looking at the angles $S_{I}$ and $5_{J}$ (Fig. 1). If $\cos \theta_{T}>0$ and $\cos a_{J}>0$, then the two surfaces can "see" each other. This is equivalent to verifying that

and

$$
\bar{r}_{[J} \cdot \bar{n}_{I}>0
$$

$$
\tilde{r}_{J I} \cdot \tilde{n}_{J}>0
$$

For plane quadrilacerals, it is necessary to verify these dot prociuct inequalities for all vectors $\bar{c}$ connecting the four corner points between the two surfaces, a total of $16 \hat{\mathrm{r}}$. If Eqs. (B) are not sacisfied for all $r_{i j}: i=1,2,3, \dot{4} ; j=1,2,3,4$, then there is total self shadowing. If Eqs. ( 8 ) are satisfied for some $\hat{r}_{1 j}$, then there is partial self shadowing.

Third surface shadowing can be detected by decermining if a line connecting the centroids of the two surfaces for which a view factor is being calculated intersects orher enclosure surfaces. The accuracy of this detection schene can he improved if the lines connecting the corner $p$, s of the quadrilaterals are also chezked for incessection with other enclosure surfaces. Unless those surfaces that can be shadowing surfaces are flagged on input to the cornpucer code, all enclosure surfaces must be checked for each pair of surfaces for which a view factor is being calculated. This is a verv time consuming operation.

The view factor can be calculated by the AI method, Eq. (2), wen partial self shadowing or third surface shadowing exists. The two surfaces, Fig. 9, for which a vieu factor is being calculated are divided inco finite subsurfe. .. Contributions to the gurmation in Eq. (2) are not included for those suhsurfaces in which the ray $\hat{r}_{i j}$ fails to satiofy Eqs. (8) or intersects a shadowing surface. For the configuration in Fig. ? ?, the viey factor F approacies the analytical value of $0.11562 \mathrm{l}$ ag the number of subsurfaces are increased.

The LI or MS methods can also be used to calculate the viev factor between the AI subsurfaces. Azain, a decision has to be made between accuracy and

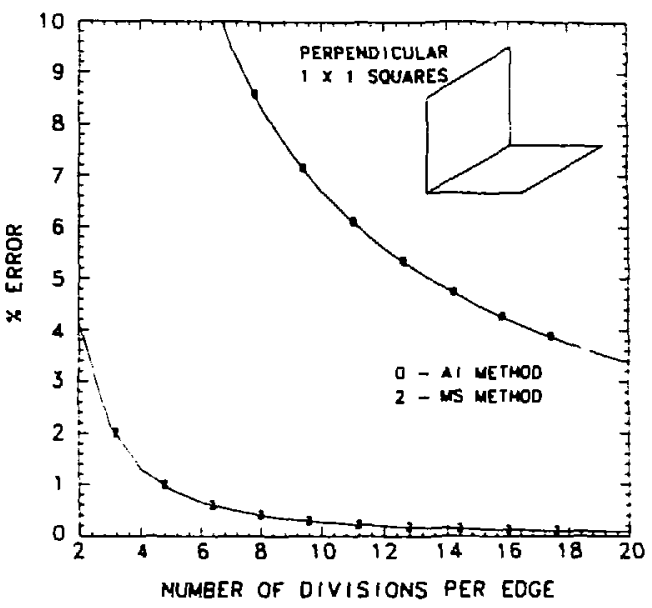

FIG. 7. THE LEAST ACCURATE NURERICAL SOLUTION EXISTS WHEN THE THO SURFACES SHARE A COHON EDGE. THE AI METHOD IS SO INACCURATE THAT IT SHOULD NOT BE USED.

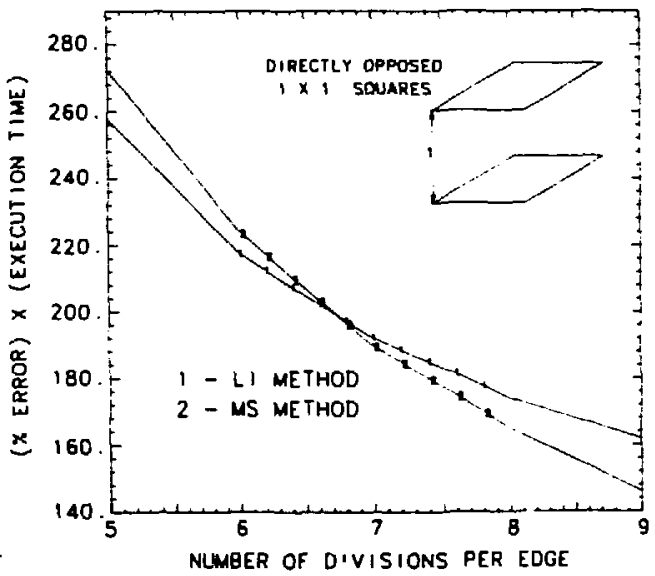

FIG. 9 BASED ON ACCURACY AND EXECUTION TTHE, THE L METHOD IS SUPERIOR TO THE MS METHOD FOR $N<7$, 


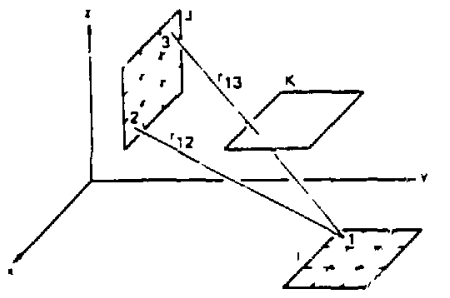

FIC. Q THIS SKETCH ILLUSTRATES THIRD SJRFACE SHADOWING. THE CONTRIBUTION TO THE "UNMATION IN EQ. (2) FOR SUBSURFACES $1-3$ AFE NOT INCLUDED BECAUSE $i_{i} 3$ INTERSECTS SURFACS $k$.

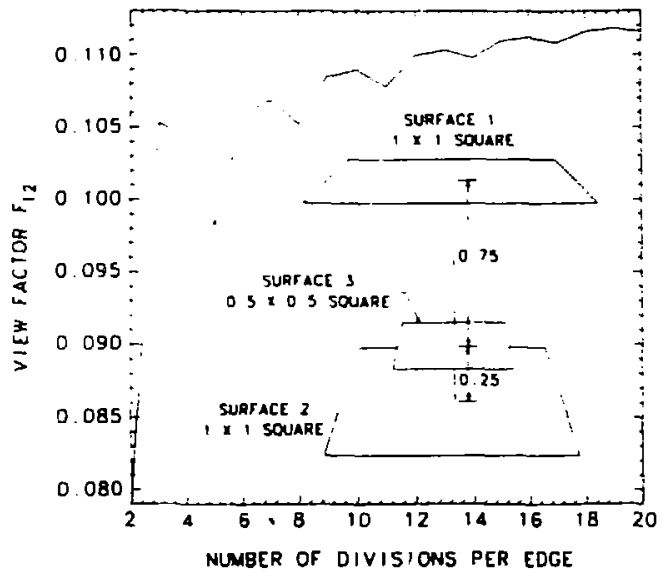

FIG. IO SURFACE 3 SHADOUS THE VIEN BETEWEEN SURFACES 1 AND 2. THE VIEW FACTOR F 2 APPROACHES THE ANALYTICAL VALUE OF 0.1 I562l AS THE NUMBER OF OIVIS IONS ARE INCREASED. computation time $i_{\text {، }}$ gelecting the best method. Since the vieu factor is being calculated between

gubsurfacea obcained by dividing an already small

finice element gtah, the Al method may provide

acisfactory results. Additionally, if the

gubsurfaces are not further subdivided (i.e. $n=1$ for the subburface), the AI method is fagter chan LI or MS.

\section{VIEW FACTOR ADJUSTIEAT}

The convergence of the AI method to the exact anawer for problems with shadoving, Fig. 10, is not a smooth function of the number of nodes used for surface subdivision. A better approximation to the vieu factor vith a savings in computer time can be calculated by a lesst squares curve fit and ixtrapolation to $n=\infty$ of the function $F_{I J}=F_{I J}(1 / n)$.

A quadratic least squares curve $f$ it and extrapolation vas tried using $F$ values for $n<10$, Conpletely erroneous results are obrained using $F_{12}$ valueg (Fig. 10) at $n=4,5$ and 6 . Selecting only monotonic $F_{12}$ values, such as for $n=4,6$ and 7 , a vieu factor of $F_{12}=0.118429$ (2.272 error) vas calculated in 0.08 seconds.

At $n \geq 10$, where $F_{12}$ is approaching a 1 inear function in $n$, a linear least squares eurve fit and extrapolation gave satisfactory resules. A value of $F_{12}=0.113671$ ( 1.692 error) was calculated for the configuration of $F_{i g} .10$ using $F_{12}$ values at $n=10,11$ and 12. The three vieu factor calculations, curve Eit and extrapolation required 3.44 seconds of compucer time. 61.5 seconds of computer $t i m e$ with $n=30$ are required to calculate the vieu factor uith the same accuracy vithour a curve fit and extrapolation.

\section{CONCLUSIONS}

The geometric surface to surface black body radiation vieu factor can be numerically calculated by either area or line incegrocion algorithms. The area integration method is so inaccurate that it should not be used when the two surfaces have an unshadowed vieu of each other. Computer implementation of the line incegration method proposed by Sparrou ( 5 ) is vectorized bu the CRAY compiler. As a result of vectorization, Sparrou's method having more restrions is faster then the line incegration method of Mitalas and Stephenson (4). Houever, the Mitalas and Stephenson method having one of its line integrals performed analyticaily is more accurate. Based both on accuracy and computer time, Sparrow's method is superior over the range of zontour subdivisions typically used.

The area interration method should be used when partial self shadouing or third surface shadouing exists. The convergence of the area integration method to the exact ansuer is not a smooth function of the number of nodes used for surface subdivision. A linear least squares curve fic and extrapolation to $n=\infty$ of the function $F_{I J}=F_{1}(1 / n) r^{2}=\cdots 1 r s$ in a better approximation to the vieu factor vith a savings in compucer time.

\section{ACKNOHLEDGEMENTS}

This work uas performed at the Laurence Livermore National Laboratory under the Department of Mechanical Engineering. Methods Development Group, for the U.S. Department of Energy under contract number $W-7405-E n g-48$. 
REFERENCES

1. R. L. Wang, "Uger's Manual for CNVuFac - The General Dynamics Heat Transfer Radiation Vieu Factor Program", Universicy of California, Lavrence Livermore National Laboratory, UCID-I 7275 (1976).

2. E. F. Puccinelli, "View Factor Computer Program (Program VIEW) Uger's Manual", Goddard Space Fiight Center, Greenbelt, MD, $x-324-73-272$ $(1973)$.

3. A. F. Emery, "Instruetion Manual for the Program SHAPEFACTOR", Sandia National Laboratories, Livermore, Ca., SAND80-8027 (1080),

4. C. P. Micalas and D. G. Stephenson, "FORTRAM IV Programs to Calculate Radiant Incerchange Factors". National Research Council of Canada, Divigion of Building Research, Ottaua, Canada, DBR-25 (1966).

5. E. M. Sparrou and R. D. Cess, Radiation Heat Transfer, McGraw Hill, New York (1078).

6. CRAY-1 Computer System CFT Reference Munual, Crav Research Incorporaced, Bloomington, $M$, publication No. $22400 n$ ? (19?8).

\section{DISCLAIMER}

This report was prepared as an account of work sponsored by an agency of the Uniled States Government. Neither the United States Government nor any agency thereof, nor any of their employees, makes any warsanty. express or implied, or assumes any legal liability or roponsibility for the accuracy, completeness, or usefulness of any information, apparatus, product, of process disciosed, or represents that its use would not infringe privately owned rights. Reference herein to any specific commercial product, process, or service by trade name, trademark. manufacturet, or otherwise does not necessarily constitute or impl; its endorsement, recommendation, of favoring by the United States Government or any agency thereof. The views and opinions of authors expressed herein do not necessarily saaic or reftect those of the United States Government or any agency thereof. 